\section{MYOPIA ASSOCIATED WITH OPACITIES OF THE CORNEA.*}

\section{WALTER L. PYLE, A.M., M.D.} PHILADELPHia.

Although the association of myopia with opacities of the cornea, as well as with opacities of the crystalline and its envelopes, has been recognized for over a half century, little mention of this fact is found in modern ophthalmic literature. Among the authors of recent ophthal. mic text-books in English, it is practically ignored.

The prevalence of corneal opacities in the cases of myopia studied in the older Continental schools and clinics is most striking to a modern American ophthalmologist. The statistics of $\mathrm{Cohn}^{1}$ show a percentage of nearly 100 in school children. Among Arlt's ${ }^{2}$ patients the association was found in 70 per cent. Additional published statisties are as follows: Chauvel, ${ }^{3} 49.7$ per cent.; Petersen, ${ }^{4} 48$ per cent., and Frenkel, ${ }^{5} 38.5$ per cent. Among other writers on this subject are Donders, Nicati, ${ }^{8}$ Werth, Landolt, ${ }^{7}$ Gelpke, ${ }^{8}$ Roure, ${ }^{9}$ Manguis, ${ }^{10}$ Hess, ${ }^{11}$ Fortin, ${ }^{12}$ Garipuy, ${ }^{13}$ de Lapersonne, and Widmark. ${ }^{14}$

Donders observed frequently the betterment of vision by concave lenses in cases of corneal opacity, but I can find no evidence to show that he recognized the production of a true axial myopia. The beneficent effect on vision was likely attributed to the increased accommodative effort and the consequent contraction of the pupil, diminishing the amount of diffuse illumination. However, Van Wyergarden, ${ }^{15}$ a pupil of Donders, in 1854, records the case of a patient, blind since infancy in one eye with pronounced corneal opacities in the other, making it necessary for him to work at very close range, who gradually developed a high degree of myopia. He also mentions a man of 42 , who improved his vision, dulled by corneal opacities, first by a stenopeic slit, and finally by concave lenses.

Arlt $^{2}$ discussed the rôle of central corneal and lenticular opacities in his celebrated Hand Book. Arlt had an especial interest in this subject, as his own brother suffered corneal opacities in a hyperopic eye, following smallpox in infancy. At the age of 13, this eye became myopic, gradually increasing in ametropia during his student life until it developed a myopia of $1 / 6$. The other eye remained hyperopic.

Several of the early writers attributed the myopia to the increased curve of the diseased cornea. von Graefe ${ }^{16}$

* Read in the Section on Ophthalmology of the American Medical Association at the Fifty-eighth Annual Session, neld at Atlantic City, June, 1907.

1. Untersuchungen der Augen von 10,060 Schulkindern, Leipzig, $1867,156$.

2. Díe Krankheiten der Augen, Prag, 1855, 1, 260; 1il, 217, 242.

3. Etudes ophthalmologiques. Recueil d'ophthalmol., 1892, 586 ;

1893, 211.

4. Ueber Hornhautflecke als Ursache der Myopia und Anisometropia, Kiel, 1887.

5. Sur les Rapports de la Myople avec les Tales de la Cornée,

Annal. d'ocul., Paris, 1904, cxxxil, 174.

6. Gaz. bebdom. de Méd. et Chir., 1879, 695.

7. Arch. d'ophthal., 1884, 1.

8. Die Augen d. Elementarschüler z. Karlsruhe, Tübingen, 1891. 9. Myopie, Cataractes centrales et Leucomes centraux, Annal. d'ocul., Paris, 1896, cxili, 393.

10. Contribution a l'étude de la Myople monolaterale. Thèse de

Paris, 1893, 94.

11. Handbuch d. g. Augenheilk., 1902, il, 338.

11. Handbuch d. g. Augenhellk., 1902, 11, 338.
12. De la Myopie acquise dans 1. Lesions cicatricelles de la Corné, Paris, 1902

13. Du Rapport d. Taies de la Cornée avec la Myople, Toulouse, 1903 .

14. Contribution to the Etiology of Myopia, British Med. Jour., 1902 , li, 1345.

15. Arch. f. ophthalmol., 1854, 251.

16. Arch. f. ophthalmol., 1854, 298. recognized the existence of a true axial myopia in these cases, and, in common with Arlt, advanced as a reason the closeness to the eye with which objects were held in order to increase the size of the retinal images, thus supplementing their want of clearness. The later statistics of Petersen and Fortin, showing a large percentage of double myopia in cases of unilateral opacities, seemed to further confirm the theory of excessive convergence as the chief etiologic factor in the myopogenesis. As will be seen later, the observations of H. Frenkel and Widmark point strongly to the accommodative strain as the cause of the myopia. These observers cite many instances of unilateral myopia with unilateral opacities.

In his-magnificent and classical study of the examination of the eyes of 10,060 school children, $\mathrm{Cohn}^{1}$ found 211 children with corneal opacities following the socalled scrofulous affections. Nearly all were myopic, and in 91 there was well-developed posterior staphyloma. Twelve were not refracted. The statistics relative to the other cases are as follows:

51 had myopia of from 1.0 to $1.5 \mathrm{D}$.

57 had myopia of from 1.75 to $2.25 \mathrm{D}$.

40 had myopia of from 2.5 to $3.0 \mathrm{D}$.

26 had myopia of from 3.25 to $4.0 \mathrm{D}$.

16 had myopia of from 5.0 to $6.0 \mathrm{D}$.

6 had myopia of $7.0 \mathrm{D}$.

3 had myopia of $9.0 \mathrm{D}$.

In 1879 , Nicati ${ }^{8}$ found among the school children of Marseilles 15.5 per cent. with myopia; and of these a large number showed corneal opacities, pronounced astigmatism and lesions of the ocular fundus, diminishing visual acuity. In 1884, Landolt ${ }^{7}$ called attention to the frequency with which corneal opacities are found associated with myopia.

In $188 \%$, Petersen ${ }^{4}$ found in the records of the Ophthalmic Clinic of Kiel reports of 186 cases of myopia with corneal opacities. In 120 cases the corneal lesions were bilateral; in 66 , unilateral. Of the bilateral cases 76 (63.4 per cent.) showed double myopia, in 28 cases higher than $6.0 \mathrm{D}$. There were 8 cases of malignant myopia, and in 50 cases there was posterior staphyloma. Bilateral emmetropia was noted in 8 cases $(6.7$ per cent.), and bilateral hyperopia in 16 cases (15 per cent.). In 66 cases of unilateral corneal opacities reported by Petersen, myopia was found in both eyes in 22 (32 per cent.). In 9 of Petersen's cases the myopia was found only in the sound eye and in 2 only in the affected eye. There was double emmetropia 3 times and double hyperopia 13 times. In 1892, Chauvel ${ }^{3}$ contributed an important statistical study showing conclusively that, besides astigmatism of the cornea, opacities of this membrane have a marked influence on the production of myopia. Of 349 cases examined in military service the opacities had appeared:

Between infancy and 5 years, 131 times.

Between 5 and 10 years, 60 times.

Between 15 and 20 years, 33 times.

During military service, 94 times.

In comparison the statistics of Fortin show the début of the corneal lesions in 23 cases before 20 years and in 12 cases after this age.

In 1893, Manguis ${ }^{10}$ reported 180 cases of unilateral myopia, in 27 of which there were corneal opacities in the myopic eye. He attributed the myopia to ciliary spasm arising from reflex irritation of the corneal inflammation rather than to the use of the eyes at very close range. In 1896, Roure $^{2}$ cites several instances in which 
concave lenses markedly improved the vision of persons with central corneal opacities not completely obscuring the whole pupillary area.

Inspired by de Lapersonne, Fortin, ${ }^{12}$ in 1902, presented a most comprehensive statistical study of 54 cases, in 26 of which the opacities were bilateral. Of these $\mathbf{1 6}$ showed myopia in both eyes (62 per cent.). In 28 instances of unilateral opacities there were 17 cases of double myopia ( 60 per cent.). The myopia appeared only on the sound side twice, and on the affected side 4 times. There was a total of 83 per cent. of myopia in the 28 sases of unilateral opacities studied, in comparison with a total of 40 per cent. in the earlier statistics of Petersen. In the second edition of the Graefe-Saemisch Handbuch, Hess ${ }^{11}$ discusses the manner in which corneal and stationary lenticular opacities cause myopia, attributing it to the necessary bringing of near objects close to the eyes.

From notes of 6,000 cases in private practice, Widmark $^{\mathbf{1 4}}$ made a study of 100 cases of anisometropia in which there was either myopia in one eye only of at least 2.0 D., or myopia in both eyes but with a difference of $2.0 \mathrm{D}$. While the purpose of the paper is to refute the prominence formerly given to excessive convergence in myopogenesis and to give proper credit to anisometropia and corneal astigmatism as etiologic factors, it contains much data distinctly relevant to the discussion of the rôle of corneal opacities in this connection. Widmark contends that when corneal defects occur in both eyes they are predisposing causes to double myopia, not on account of the excessive convergence required, but because both eyes are strained in the effort of near vision. On the other hand, he affirms that when the cornea of but one eye is affected its fellow only becomes myopic, because it assumes all the strain of close work. He believes that the affected eye may beeome amblyopic, divergent or convergent, or may even be enucleated without in any way influencing the course of the myopia in its sound fellow. In support of this contention he cites several interesting illustrative cases, in 4 of which unilateral opacities caused myopia on the sound side only. This is confirmative of the belief shared by Arlt, Werth and Petersen, and which is disputed by the findings of Fortin and Frenkel and, in a measure, by the statistics that I offer. Widmark argues that the chief cause of myopia is seeing "in a limited sense"-the perception in the yellow spot and processes connected therewith at the posterior pole of the eye. Any extra effort at discerning close objects quickly following on each other-as, for instance, in reading and writing-may lead to hyperemia in the ocular fundus, which some writers assume as the predisposing cause of the characteristic myopic changes at the posterior pole. In addition the accumulation of fatigue products may also have a deleterious influence on the intraocular membranes, the continued hyperemia leading to softening of the tissues, which yield to the intraocular pressure. The practical lesson from these observations is the great necessity of facilitating the work of the retina and preventing ocular fatigue by correction of the astigmatism, anisometropia, etc., adequate illumination, properly printed books, etc. Other hygienic measures are relatively unimportant in controlling myopogenesis in school children.

By far the most exhaustive bibliographic and clinical study of this subject is that by $\mathrm{H}$. Frenkel, ${ }^{5}$ of Toulouse, supplemented by the ophthalmometric measurements of his associate, E. Garipuy. ${ }^{13}$ The cases were selected from
1,350 ophthalmic patients. Among the patients with corneal opacities there were found:

10 men and 20 women with myopia.

4 men and 4 women with emmetropia.

4 men and 5 women with hyperopia.

Of 22 patients with bilateral corneal opacities there were 14 with double myopia (63.6 per cent.), proportionately identical with the findings of Petersen and Fortin. There was unilateral myopia twice, and in 3 cases in one eye determination of the refraction was impossible. Of the 22 cases there were 19 instances of myopia, either unilateral or bilateral (86.4 per cent.). In one case there was practical emmetropia and in two cases hyperópia. In the 25 cases of unilateral opacity Frenkel found a preponderance of myopia on the affected side 11 times. In 2 cases the myopia was on the sound side. To summarize, there were 13 cases of myopia, 5 cases of emmetropia, 2 cases of double hyperopia, 3 cases of hyperopia on the affected side, and 2 cases of hyperoopia on the sound side.

Illustrative of the tendency to high myopia, Frenkel found myopia above $6.0 \mathrm{D}$. in 16 of the 78 patients with corneal opacities-a proportion of 20.5 per cent., as against 6.45 per cent. in all the cases of myopia (about 1,000 ) observed by Cohn among 15,490 patients from 1866 to 1886 (reported by Schlesinger ${ }^{17}$ ). This marked frequency of high myopia may be attributed to the greater liability to affection of the intraocular membranes of the posterior segment of the eyeball after serious disease of the anterior tunics - a fact established by the observations of Panas ${ }^{18}$ and de Lapersonne. Frenkel also significantly mentions that he has found corrected visual acuity relatively better in the cases of hyperopia with corneal opacities than in those of myopia. It is considered justifiable to believe that certain lesions of the cornea and anterior segment of the eyeball have associated with them a disturbance at the posterior pole, which, by an ill-defined, but nevertheless real, process, results in a chorioretinitis which becomes a preponderating factor in the pathology of progressive myopia.

It has also been suggested in this connection that irritation of the ciliary body following corneal inflammation produces hypersecretion and disturbance of the equilibrium between the ocular membranes and intraocular tension, resulting in a veritable anterior staphyloma, such as is seen in some cases of congenital hydrophthalmos. Fortin claims to have observed several cases of myopia in which there was an exaggeration of the corneal curve resembling that of true keratoconus. The ophthalmometric measurements in Frenkel's cases, however, did not show any significant difference between the curve of the central corneal meridian in the myopic cases with corneal opacities and that of the cases of hyperopia or emmetropia with similar opacities.

A careful study of the relative literature, as well as personal observation, shows that in these cases the myopia may appear either in the sound or diseased eye, or in both eyes. Frenkel states that in the cases of unilateral opacity examined by him the myopia was most frequently unilateral, but not always in the affected eye. Moreover, in no instance of unilateral opacity with double myopia was the defect equal in the two eyes and imputable in both eyes to the corneal lesions. He believes that if the opacities of the affected eye do not markedly interfere with useful vision at close range this eye speedily becomes

17. Beitrage $z$, prak. Augenhellk., $1900, x l v, 127$.

18. Lecons de clinique ophthalmol. Recuelles par Castan, Paris, 1899,157 
myopic. On the other hand, if the opacities greatly obscure vision, preventing satisfactory use of the affected eye, the myopia develops in the sound eye. He calls attention to the fact that, in addition to irregular astigmatism, corncal opacities produce a definitely measurable astigmatism, which averages $1.5 \mathrm{D}$. to $2.0 \mathrm{D}$., and which is a factor in the myopogenesis. This conclusion is the result of careful ophthalmometric measurements in cases of unilateral and bilateral corneal opacities with and without associated myopia.

In 11 cases of high myopia, measurement of the anterior corneal curve showed an average astigmatism of 1.7 $\mathrm{D}$. in the right eve and 1.6 D. in the left. In the cases of bilateral corneal opacities with myopia the average astigmatism in the right eye was $1.7 \mathrm{D}$.; in the left eye, $2.0 \mathrm{D}$. In the cases of unilateral opacity the average astigmatism in the affected eye was $1.6 \mathrm{D}$.; in the sound eye, $0.8 \mathrm{D}$. In the cases of opacities with emmetropia, the astigmatism was predominant in the eye with the opacities. In the cases with hyperopia, the average astigmatism in the affected eye was $1.3 \mathrm{D}$.; in the sound eye, $0.2 \mathrm{D}$.

I have selected from my private case records for the last ten years 28 instances of corneal opacities associated with myopia; of these, 13 were males and 15 females, ranging in age from 10 to 60 years. In 22 cases the opacities were unilateral, in 6 bilateral. In the examination of my records, no myopia of less than $2.0 \mathrm{D}$. has been considered, and all cases of suspected lenticular myopia have been rejected. No attempt has been made to show the relative frequency of corneal opacities in general ophthalmic practice, and the refractive condition of all patients with corneal opacities is not considered. It is evident that there would be a great discrepancy between the statistics of an American private ophthalmic practice and a Continental clinic. The object of the paper is solely to set forth the rôle of corneal opacities in myopogenesis and to present interesting collateral and relative data. Of the 22 unilateral cases of opacity the myopia was double in 12 and single in 10 . The myopia developed only in the sound eye in 5 cases and only in the affected side in 5 . Of the 6 cases of bilateral opacities, in 2 the myopia was unilateral. In one patient with congenital bilateral central posterior capsular cataracts, the myopia was unilateral and the corrected visual acuity was equal and almost normal in the two eyes. In one case of bilateral opacities the myopia was unilateral and in the eye with least opacity. In one case of double opacities, the myopia was bilateral and greatest in the eye with the best vision. Of the 16 cases of bilateral myopia there was a difference in the two eyes of more than $3 \mathrm{D}$. in 6 cases.

Unfortunately the opportunity to observe continuously the development of the myopia has been limited, but in two eases repeated examinations extending over a decade are of sufficient interest to warrant recording. In 1897 the patient, a girl of ten years, came to my office complaining of poor vision in the right eye, which was found to contain several punctate corneal opacities. There was a history of repeated attacks of "sore eyes" and the conjunctiva showed marked evidence of argyrosis. The refraction under atropin was:

R.-S. $2.00-$ C. 1.00 ax. $180^{\circ}=6 / 12 \nabla$.

L.-S. $0.25-$ C. 0.37 ax. $30^{\circ}=6 / 5 \mathrm{~V}$.

Within the next two years there were several slight attacks of phlyetenular conjunctivitis in the right eye which always yielded promptly to the ordinary treatment.
In 1902 the patient complained of failing vision in the left eye. Under cycloplegia I found:

R.-S. $2.50-$ C. 1.00 ax. $180^{\circ}=6 / 7 \%$.

L.-S. $2.00-$ C. 0.62 ax. $180^{\circ}=6 / 5$.

The opacities gradually disappeared until the examination of the refraction under atropin in 1907 showed perfect visual acuity in both eyes, with the following refraction:

$$
\begin{aligned}
& \text { R. S. } 3.00-\text { C. } 1.25 \text { ax. } 180^{\circ}=6 / 5 \text {. } \\
& \text { L.-S. } 2.50-\text { C. } 0.50 \text { ax. } 180^{\circ}=6 / 5 \text {. }
\end{aligned}
$$

In this case, at first appearance, the myopia was distinctly unilateral and in the affected eye, but during the course of school work, notwithstanding repeated refractions and the rigill use of correcting lenses, an almost equal degree of myopia developed in the sound eye. Fortunately the corneal haze gradually disappeared in the right eye until the corrected visual acuity was ultimately practically as good as that of the left eye.

Another interesting case was in a boy of 10 , who first consulted me nine years ago. There was a faint central corneal opacity in the left eye following a severe keratitis in early chilhood. Retinoscopic and ophthalmometric measurements showed 1.75 D. of hyperopic astigmatism at the vertical axis. The opacity was sufficiently dense and the cornea irregular in curvature to prevent vision better than 6/100, even with the correcting cylindric lens. The sound right eye was myopic to the extent of $1.5 \mathrm{D}$., but with the correcting lens visual acuity was perfect. During the last nine years the myopia of the sound right cye has gradually increased to $4.0 \mathrm{D}$, with no diminution of corrected visual acuity. The opacity in the left cornea has gradually diminished, allowing an increase of corrected visual acuity to $6 / 30$, without, however, any noticeable change in the refraction.

\section{CONCLUSIONS.}

1. Central corneal opacities are a much more frequent cause of myopia than would be inferred from an examination of general ophthalmic literature, particularly the English and American text-books and periodicals. According to recent reliable Continental statistics, in at least one-third of the cases in which they are present, central corneal opacities produce myopia, although this average is likely higher than that found in American ophthalmic practice.

2. The myopia is axial and not dependent on alteration of the corneal curve. Ophthalmometric examinations do not show any significant differences between the corneal curvature of myopic eyes with corneal opacities and similar eyes in which the refraction is emmetropic or hyperopic.

3. The mechanism of the production of the myopia is analogous to that of the common form following astigmatism, anisometropia, ete., with the added predisposing factor of weakened ocular tunics by previous inflammation.

4. The association of disturbance of the chorioid and retina of the posterior segment of the eyeball with inflammations of the anterior membranes is an important element in further reducing visual acuity in these cascs. For a similar reason extensive fundus lesions are common, and the myopia is more likely to become progressive than ordinary.

5. Either unilateral or bilateral opacities may produce myopia, and the myopia produced may be unilateral or bilateral.

6. In the cases of unilateral opacity the myopia may be single or double. If in such cases the myopia is uni- 
lateral it may appear either on the sound or the affected side, but no definite rule can be established in this connection. However, it is likely that when one eye is used almust exclusively for close vision it will become myopic first or to a greater extent than its fellow.

7. In cases of bilateral corneal opacities the myopia is generally bilateral. When there is a marked difference in the amount of defect in the two eyes the greatest myopia is often found in the eye with the least corrected visual acuity. When the myopia is unilateral it often oecurs in the eye with the least opacity.

8. The cases of unilateral myopia are strongly suggestive of the importance of ciliary strain rather than excessive convergence in myopogenesis.

9. In view of the strong possibility of resultant myopia, all cases of corneal disease, particularly the phlyctenular affections of childhood, should receive prompt and continuous treatment, and prophylactic measures should be rigidly followed to prevent recurrences. After the subsidence of the inflammation energetic treatment should be adopted to clear up the opacities.

10. Of greatest importance in the prevention of the subsequent myopia is careful and repeated refraction of both eyes under artificial cycloplegia, employing both objective and subjective methods, and the constant use of correcting lenses.

11. All errors in ocular, personal and domestic hygiene that encourage the development of myopia should be corrected, and the patient should be kept in the best physical condition and most salutary environment.

\section{Clinical Notes}

\section{THE GYMNASIUM IN THE CAMPAIGN AGAINST DISEASE.}

THOMAS A. STOREY, M.D. NEW YORK CITY.

The education of the masses in matters of personal and general hygiene gives the greatest promise of success in our modern campaign against disease. The category of preventable diseases is large and their prevention is generally easily possible under proper personal and general hygienic regulations. In fact, it is certain that a reasonable hygienic regimen imposed for a long period of time and imposed on all individuals in any given region will result in the eradication in that region of certain diseases that are now widely prevalent. It is with a full realization of this fact and of the uselessness of much of our present mortality that prophylactic medicine has of late years become so active. Our textbooks on medicine reiterate again and again the necessity for careful hygienic regulation in the prophylactic measures laid down for each disease. Physicians are advising their patients more and more concerning the relation of daily hygiene to health. Boards of health are vitally interested in the proper hygienic regulation of the conditions under their supervision, and these several influences are striving to secure the intelligent cooperation of the masses by teaching them the significance of hygiene. Societies are formed, literature is disseminated, lectures are given and stereopticon illustrative views are shown in public places in order to educate the people. Legislative enactment with an absolute control over a large number of disease-breeding conditions is bound to follow popular enlightenment. In this educative campaign, as has been noted, several forces are now active. More should and will be added. This article is written in order to point out another which I believe would be a powerful ally. Our higher institutions of learning exert a very strong and widespread influence in all matters in which they are concerned. The students in attendance are drawn from the four corners of the earth, and after several years of academic experience are scattered again to become active participants in all phases of life. If each student after leaving college would become an active element in the campaign against disease the educative work done in any given academic community would be efficiently and enormously multiplied. In the modern high school, college and university there is a department in which personal and general hygiene logically belongs. Physical instruction is nothing less than personal hygiene, and gymnasium work is applied hygiene. Nowhere in an academic community is there an easier opportunity to meet large numbers of students than in the gymnasium. Nowhere else is instruction in the simple laws of hygiene more logically placed. Nowhere else than on the gymnasium floor before a class of men do you find the "psychologic moment" for making appropriate statements that will be remembered. Five minutes before each drill--not a lecture-and in one year or two years enough will have been said and remembered to make the gymnasium a jowerlul foree in the campaign against disease.

\section{ESBACH'S ALBUMIN TEST COMPLICATED BY} KREATININ.

\section{W. J. CALVERT, M.D. COLUMBia, Mo.}

Incomplete precipitation of albumin in Esbach's test is mentioned. One .reason for this partial precipitation was observed in a rapidly fatal case of typhoid. A small amount of albumin was constantly present which gave a small precipitate in the Esbach's tube, but the fluid in the tube remained cloudy for days. With the assistance of Dr. W. Koch, it was found that a very large amount of kreatinin was present. Kreatinin gives with picric acid, in an acid solution (as citric acid), a yellow precipitate which remains in suspension for a long period of time. Perhaps this reaction explains the incomplete precipitation in other cases.

\section{A CASE OF ACUTE APPENDICITIS,}

FOLLOWED BY EMBOLISM OR TIROMBOSIS OF LEET EXTERNAL ILIAC ARTERY, WITH DRY GANGRENE OF LEFT FOO' AND LEל.

RANDOLPH WINSLOW* A.M., M.D. Professor of Surgery, University of Maryland. BALTIMORE.

History.-Sept. 17, 1906, Mr. G., aged 57, a large, fat, previously active and supposedly healthy map, was attacked with pain in the abdomen. He went to his store on the morning of September 18, but was unable to remain the whole day, and I was summoned to see him in the evening. He was suffering considerabte pain in the abdomen, which was rigid in the appendiceal region, with marked tenderness on pressure over appendix. There was fever and acceleration of pulse to a moderate degree. This man had enjoyed exceptionally good 